\title{
EL CARDENAL PUENTE (1808-1867), DESDE CÁDIZ, EN TRES LÍNEAS DIVERGENTES EN EL SIGLO XIX ESPAÑOL
}

\author{
POR
}

Alfredo Martínez Albiach

Madrid

\section{Resumen}

El autor examina la trayectoria de tres gaditanos que convivieron y coincidieron en parte en el tiempo que les tocó vivir, cada uno en un ámbito y con talante muy distinto: el militar Luis Fernández de Córdova, el político Mendizábal y el obispo De La Puente, que lo fue de Salamanca y Burgos.

\section{Abstract}

Cardinal Puente (1808-1867), from Cadiz, inside three divergent lines from the $X I X^{\text {th }}$ spanish century.

The author examines the life of three Cadiz men who lived in the same time and in similar circunstances but with different trajectories: general Luis Fernández de Córdova, Álvarez de Mendizábal, politician, and De La Puente, who was the bishop of Salamanca and Burgos.

\section{PreÁmbulo}

De Cádiz parten tres líneas - representantes de vivencias personales- que, si bien en un plano accidental coinciden (en 1820, cuando la primera reimplantación de la Constitución de 1812; también en 1836, con motivo de la 
"Quinta de Mendizábal"' durante la guerra carlista; etc.), se van apartando sucesivamente unas de otras: líneas divergentes. Las tres, teniendo su cuna familiar en Cádiz, representan un nuevo modelo profesional para el siglo en que viven - el XIX —; Juan de Dios Álvarez Méndez Mendizábal, Luis Fernández de Córdova Valcárcel, y Fernando de la Puente y Primo de Rivera: un político, un militar, y un cardenal. Tres líneas divergentes que nunca -pese a la buena voluntad, muchas veces manifestada - lograron entenderse entre sí. Mas, como insinuamos, la impronta que cada uno marcó en su profesión no sólo fue indeleble, sino que planteó una vivencia nueva para un siglo -el XIX -, que tanto influirá en la posteridad: en la política, en lo castrense y en la Iglesia española.

Las tres líneas divergentes partieron, pues, de la ciudad, piropeada popularmente por "tacita de plata", y por el poeta Pemán" "señorita del mar", "salada claridad" según la anotación de Manuel Machado, sin olvidar a Juan Ramón Jiménez -"Aireario" por su sabiduría de aire y por su erudición de vientos (levante, poniente o nortada en Ia diaria conversación gaditana)-, García Sanchís --pañuelo blanco que despide al navegante"-, Edmundo d'Amicis - "gaviota con las plumas revueltas tras un remojón"--, lord Byron -"sirena del océano"-, etc.

Si en el discurso inaugural de las Cortes gaditanas de Diego Muñoz Torrero (24-IX-1810) hace apostillar a Benito Pérez Galdós (1843-1920) la frase3: "El siglo XVIII había concluído. El reloj de la historia señaló con campanada, no por todos oída, su última hora, y realizóse en España uno de los principales dobleces del tiempo". Sin embargo, en aquella centuria decimonónica algunos permanecieron sordos ante dicho reloj (en etapas de absolutismo fernandino). Pero ya había caído el telón del Antíguo Régimen y difícilmente se puede dudar ante la ingenua descripción de Fernando F. de Córdova acerca de su abuela paterna ${ }^{4}$ : su mismo nieto lo reconoce antes de morir en 1883. Mas en los albo-

1 Fernando Fernández Bastarkeche, José Cepeda Gómez, Enrique Martínez Ruta, Las fierzas armadas. La era isabelina y el sexenio democrático (I834-1874). Historia de España, Espasa Caipe S.A., Madrid 1988, $2^{\text {a }}$ edición, t. XXXIV, p. 529. Fernando FERNÁNDEZ DE CóRDOVA, Mis memorias íntimas, Establecimiento Tipográfico "Sucesores de Rivadeneyra", Madrid 1886-1889, t.I, p. 263.

2 José María Pemán, Andalucía, Ed.Destino, Barcelona 1966, $2^{a}$ ed., p.306-309.

3 Benito PÉREz Galdós, Cádiz. Episodios Nacionales, Ed. Nauta S.A., Madrid 1989, t.Il, p. 714-717.

4 Córdova, Ibidem (lb.), I, 29: "Mi abuela paterna, doña Julia de Rojas (...) era una señora en quien lo ilustre de su cuna y la alta posición de su marido (D. José Femández de Córdova y Ramos de Garay, teniente general de la Real Armada) habían desarrollado el orgullo de raza (hija de D. José de Rojas, Conde de Casa-Rojas, capitán general del departamento de Cartagena de Levante y presidente de su Real Chancillería), y pretensiones, llevándolas a un extremo no admitido en esta época (antes de 1883), aunque en aquélla era achaque regular y corriente. En Cádiz solía llevar como muchas damas

La América y la España Conternporánea

Hispania Sacra 49 (1997) 
res del XIX costó mucho que el eco de aquella campanada se abriera paso en el tiempo.

\section{Mendizábal y Luis F. DE CóRDOVA}

\subsection{Primeras actividades políticas de Mendizábal.}

Parece que, al casarse, cambió su segundo apellido (Méndez) por el universalmente conocido de Mendizábal: había nacido en febrero de 1790, en la ciudad gaditana, dentro de un hogar de comerciantes - ropavejeros-- portuarios judíos. Desde joven entró en el mundo del comercio y de las finanzas, como empleado de banca, y posteriormente en la administración militar -excepcional conocedor de los problemas hacendísticos - durante la guerra de la Independencia. Fallecería en Madrid, en noviembre de 1853.

Aún en su juventud, si no podía llegarle el eco de los elogios que la sociedad en general, y algunos oradores eclesiásticos en particular (como Felipe Rodríguez desde Toledo, y José María Valenzuela en Mérida ${ }^{5}$ ) a Godoy, príncipe de la paz y grande almirante, no pudo desoír - tras la derrota de Trafalgar- las "Oraciones fúnebres" de 21-XI-1805 y 29-V-1806 en las iglesias gaditanas de Nuestra Señora del Carmen y en la de los Carmelitas Descalzos: éstos metamorfoseaban aquella derrota en un "combate funesto para las Armas Británicas", a la vez que comparaban a Gravina con "el intrépido Bonaparte"6. Tampoco dejaría de percibir el cambio de veleta política del partido fernandino en El Escorial, sobre todo desde el matrimonio del príncipe Fernando (4-X1802) con María Antonia de Nápoles (+ 21-V-1806), hasta la abdicación de Carlos IV en su hijo Fernando (Aranjuez, 19-III-1808)

\footnotetext{
de su tiempo, a guisa de cinturón, el fajín rojo con los entorchados de teniente general de su marido, y siempre que salía a la calle, bien a paseo por la muralla del mar, bien en coche por Puerta de Tierra, haciase rendir los honores que al general su marido por ordenanza correspondían, de todas las guardias, tropas u oficiales sueltos que a su paso encontraba. Muchas veces he oído relatar a mi madre el hecho, muy comentado en Cádiz, de haber arrestado aquella señora en banderas, cierto día, al capitán del principal situado en la plaza de San Antonio, por haber omitido a su paso, el desgraciado, formar la guardia y batir marcha. No tuvo más hijo que mi padre, al que siendo mozo y guardia marina, arrestaba también frecuentemente, ora con objeto de corregir sus faltas militares, ora con el de impedirle viera a su novia y mi madre, pues hacía entonces guerra sin cuartel a aquel enlace."

5 Alfredo MARTínEZ ALBIACH, Religiosidad hispana y sociedad borbónica, Facultad teológica, Burgos 1969, 160-166; IDEM (ID.), Talante del catolicismo español, Fac. teológica, Burgos 1977, 65.

6 M. ALBlaCH, Religiosidad..., 166-169

7 Manuel IZQUIERDO HERNÁNDEZ, Antecedentes y comienzos del reinado de Fernando VII, Ed. Cultura Hispánica, Madrid 1963, 215-317. M. AlBıACH, Talante..., 73.
} 
eclesiástico de José María de la Miera Pacheco al atardecer del 18-III-1808 en la real Capilla de San Antonio de Aranjuez: allí predicó Pacheco contra el "valido infame y traidor", si bien tal sermón no se publicaría hasta 1809 , considerado como "primer holocausto ofrecido en las aras de la Patria, qüando (sic) este acto era qüal (sic) fue para mí un crimen imperdonable"8.

Y además la triunfal entrada de Fernando VII en la corte (26-III-1808); y su búsqueda de la aprobación de Napoleón (desde el 16 al 20 de abril de aquel 1808, que duró su viaje de Madrid a Bayona), donde la corona hispana volvía a las sienes de Carlos IV, y luego a Napoleón para cederla a su hermano José Bonaparte. Ante la huida del infante Antonio Pascual de Borbón (1755-1817, hijo segundo de Carlos III), a quien su sobrino Fernando VII había dejado en Madrid presidiendo la Junta de Gobiemo, ésta aceptó la autodenominación presidencial de Joaquín Murat, duque de Berg, con el posterior refrendo según el decreto firmado por Carlos IV.

El levantamiento del pueblo de Madrid (2-V-1808) y su represión por $\mathrm{Mu}$ rat, pintados por Goya (desde su casa de la Puerta del Sol, $\mathrm{n}^{\circ}$ 9), segundo piso, aunque luego se retiró a su quinta, junta al puente de Segovia9), trascendió incluso religiosamente al convertirlo el púlpito en guerra santa: desde Cádiz, Francisco José del Salvador mantendrá su voz hasta el 26-XI-1814 ante el propio Fernando VII ${ }^{10}$ - a todos los lugares. Por ello el pueblo se hizo depositario de una soberanía que él había sabido recoger del arroyo: precisamente esa nobleza provincial y esos elementos de la burguesía, lejos de ser otros tantos diques opuestos a la avalancha revolucionaria, iban a ser en gran parte los fautores de la revolución ulterior, que no sólo no fue llevada por el pueblo, sino, en cierto modo, contra los deseos del pueblo'11.

Y a partir de ese momento se inició una guerra política y militar en España, donde tuvo parte activa Mendizábal. Amén de la política, manifestada posteriormente como miembro masónico del "Taller Sublime"12, se halla -como ya dijimos- en la administración militar de la guerra de la Independencia desde los primeros levantamientos (Valencia, 23-V-1808; Alcalá de Henares, 1-VI1808); culminando algunos en Juntas Supremas: calificativo que Artola Galle-

\footnotetext{
8 M. ALBIACH, Religiosidad..., 171.

9 Gonzalo MENÉNDEZ PIDAl, La España del siglo XIX vista por sus contemporáneos, Centro de Estudios Constitucionales, Madrid 1988, I, 69.

10 Manuel Revuelta GonZalez, La Iglesia española ante la crisis del Antíguo Régimen (180833). Historia de la Iglesia en España, B.A.C., Madrid 1979, 7-14; M. ALBIACH, Religiosidad..., 98128, 593; ID., Talante..., 71-72, 74, 81-84

11 Carlos Seco Serrano, Introducción. La España de Fernando VII de ArTola, Historia de España, Espasa-Calpe S.A., Madrid 1989, t. XXXII, p. XII.

12 Miguel Artola Gallego, La Espana de Fernando VII, t.XXXII, p. 438-439.
}

La América y la España Contemporánea Hispania Sacra 49 (1997) 
go ${ }^{13}$ traduce por "soberanas". Y añade: "Se acaba el Antíguo Régimen: sustitución de la legitimidad monárquica por la popular; en lo sucesivo se reputarán por legítimas autoridades únicamente las creadas por el pueblo o por sus representantes".

Pese a la victoria de Bailén (19-VII-1808), sublimada por el púlpito español en mito ${ }^{14}$, con la entrada de Napoleón en España (6-XI-1808), la Junta Central -fusión de las Juntas Supremas Provinciales por el "golpe de Estado" de Aranjuez (25-IX-1808) ${ }^{15}$ - abandona Madrid (25-XI-1808) —adonde el emperador francés llega (2-XII-1808), aniversario de Austerlitz ${ }^{16}$ - para refugiarse en Sevilla (17-XII-1808). Aquí la Central pronto compite con la Junta Suprema hispalense, la cual aprovecha la derrota de Ocaña (19-XI-1909) para desprestigiar a aquélla, creando una nueva Junta Central, por to que la primera -la del "golpe de Estado" de Aranjuez, se traslada a la Isla de León (23-I1810). Y se instala el 27-I-1810, en cuya noche Tomás de Istúriz propone en Cádiz la creación de una Junta gaditana que reasuma la "soberanía". Ante tanto acoso, la primera Junta Central resigna sus poderes en la Regencia, compuesta por el obispo de Orense (Pedro Quevedo Quintana, cardenal en 1816,+ 28-III-1818), Saavedra, Escaño, Castaños y Fernández de León, con el encargo de convocar Cortes. "El Consejo de Regencia - establecido el 31-I-1810- es la creación del poder revolucionario de la Junta Central y el heredero de la nueva legitimidad"17, con Castaños de presidente (1-II-1810), a quien sustituyó (31-VII-1810) el prelado orensano.

Ante la epidemia de la fiebre amarilla en Cádiz, las Cortes se reunieron "en la Real Isla de León, el día 24 de setiembre (sic) del presente año de 1810 [...], a la hora de las nueve de la mañana [...], a la iglesia parroquial de ella [...]. Instaladas ya las Cortes [en su sala, que era un teatro], procedióse a la elección de presidente [...]. Resultó que el Sr. Dou tuvo cincuenta votos, y el Sr. [D. Benito Ramón de] Hermida qüarenta [sic] y cinco; quedando por consiguiente elegido Presidente el Sr. D. Ramón Lázaro de Dou"18.

Seguramente Mendizábal vivió aquella jomada, novelada por Pérez Galdós 19: "En la plaza de San Juan de Dios —según Ramón Solís-, el Cádiz de 1810-1813 no era muy pródiga en plazas: además de la citada, sólo nombra la

13 ARTOLA, $/ b ., 37,51,68,379$.

14 ARTOLA, Ib., 255; M. AlbIACH, Religiosidad..., 128-138; ID., Talante..., 69-71, 75-78.

is ARTOLA, $1 b ., 390,405-406$.

I6 ARTOLA, $1 b$., 309-371. REVUELTA, $1 b ., 15-33$.

17 ARTOLA, $I b ., 442$. REVUELTA, $I b ., 34-36$.

18 Diario de las Discusiones y Actas de las Cortes, Imprenta Real, Cádiz 1811, t.l, p.1-5. M. ALBlACH, Religiosidad..., 245-267.

19 Pérez Galdós, Cádiz, II, 714,717. 
enlosada y cuadrangular de San Antonio como lugar de corridas de toros, paradas militares, etc.-, los caleseros gritaban llamando viajeros: !A las Cortes, a las Cortes! [...]. En el teatro de las Isla [...], el [ya mencionado] primer discurso que se pronunció en asambleas españolas en el siglo XIX", el de Diego Muñoz Torrero, antiguo rector de la Universidad de Salamanca. Para ello, por carretera Mendizábal hubo de recorrer el camino hasta la Isla con la cegadora luz, hiriendo los ojos, mordidos por las reverberaciones del sol ante las salinas, y dejando a la derecha el lejano castillo de Sancti Petri; aquí estuvo enclavado el fabuloso templo de Hércules, que aun regala de vez en cuando al curioso investigador con algunos restos de su opulencia, enredando los aparejos de los pescadores, estatuas romanas y monedas de las que Gades - Julia Romanaacuñó en la época en que sus habitantes tuvieron la consideración de ciudadanos romanos, nacidos en la entonces tercera ciudad del Imperio.

Superada dicha epidemia de fiebre amarilla, las Cortes se trasladaron a Cádiz (20-II-1811), teniendo su primera sesión en la iglesia de San Felipe Neri cuatro días después; desde allí afrontaron los avatares de la guerra ${ }^{20}$ hasta el 2II-1814 - tras la proclamación de la Constitución (19-III-1812), también mitificada por cierta parte del púlpito ${ }^{21}$ _ al fijar su residencia en Madrid, donde el general Eguía las disolvió (10-V-1814) por orden de Femando VII ${ }^{22}$.

Durante la estancia gaditana de las Cortes ignoramos detalles acerca de la labor político-militar de Mendizábal, pero tuvo que ser discreta, pues -ante la represión fernandina ${ }^{23}$ - aparece como activo liberal y miembro masónico del citado "Taller Sublime" colaborando con Antonio Alcalá Galiano (1789-1865) en la preparación del pronunciamiento de Rafael de Riego entre 1819 y 1820 , frustrado en un primer momento en Cádiz por el joven militar Luis Femández de Córdova.

\subsection{Inicial andadura de Luis Fernández de Córdova Valcárcel.}

Nacido en 1798, en la Isla de León (llamada después de San Fernando), vivió en Cádiz con sus padres José y María de la Paz, naturales respectivamente de Cádiz y de la Isla, junto a sus abuelos paternos el teniente general de la armada José Fernández de Córdova y Ramos de Garay, y Julia de Rojas, hija de conde de Casa-Rojas, hasta 1803. Entonces, su padre, a petición del comandante general y gobernador de Montevideo, Pascual Ruíz Huidobro, quien

\footnotetext{
20 ARTOLA, $I b ., 141-306$.

21 M. AlBIACH, Religiosidad..., 323-367. REVUELTA, $I b ., 36-61$.

22 ARTOLA, $1 b$, , 471-529.

23 ARTOLA, $l b$, 529-562. REVUELTA, $l b$, , 66-83.
} 
deseando tenerle a sus órdenes, le dio el mando de la goleta La Paz, partió con su familia para tierras americanas. Según la hoja de servicios del cabeza de esta familia, José, "noticioso en Montevideo de la pérdida de Buenos Aires, tomada por los ingleses, fue el que propuso a sus compañeros de marina su reconquista [...] el día 12 de Agosto de 1806 [...]. Por Septiembre de 1809 [...], posesionado el general Vicente Nieto de la presidencia de Charcas, dio el mando de sus tropas a Córdova [...] hasta que, de resultas de la revolución de Buenos Aires, deposición de su Virrey y demás ruidosos acaecimientos, por orden del Virrey de Lima se mandó al presidente Nieto ir a sujetar a los rebeldes del Río de la Plata. En esta época dio a Córdova el mando de la vanguardia, compuesta de 2.500 hombres, la mayor parte naturales del país y de Buenos Aires [...]. Pasáronse al partido de sus naturales y sacrificaron a sus jefes, Nieto, Córdova y Sanz [...]. Córdova no murió como un simple capitán de fragata, y sí como el segundo jefe de un ejército, cuya cabeza era Nieto [...], y como tal lo fusilaron [...]. La muerte de Córdova fue en la plaza de Potosí, el 15 de Diciembre de 1810 [...], a los treinta y siete años de edad"24. Antes de emprender la viuda su regreso a España, envió a sus dos hijos mayores, José y Luis, a quienes el abuelo paterno, ya viejo y desconsolado por la muerte de su único hijo, quería tener en su compañía ${ }^{25}$.

Y desde Cádiz aguardaban la llegada de su madre José y Luis, valorando las nuevas fortificaciones gaditanas que la Regencia agradeció (25-VIII-1812): la primera necesidad que planté el sitio napoleónico, fue cambiar radicalmente sus esquemas defensivos; Cádiz reforzó las fortificaciones del citado Sancti Petri y del puente de Zuazo y construyó unas nuevas como el fuerte de la Cortadura -elaborado por todos los ciudadanos sin distincion de clase social-, donde Luis conseguiría merecida fama en 1820.

Pero, de momento, contemplamos a Luis recibiendo a su madre, conducida en una fragata de guerra, y colmada de honores y atenciones. Una tierna acogida. Tal era la sensación que produjeron sus desgracias en Cádiz, "donde nuestra familia - testifica Fernando ${ }^{26}$ - tenía su principal arraigo y parentesco. Las famosas Cortes de Cádiz, a la sazón en plena y grande actividad políti$\mathrm{ca}$, declararon héroe a mi padre por unanimidad, consignando que su memoria merecía bien de la patria, y votando para su viuda la pensión del sueldo integro de capitán de navío, recompensa nacional a que mi familia debió, sin duda, todo lo que fue después".

Mas poco duró la presencia gaditana de Luis y su hermano mayor José: "obtuvieron, por mandato expreso de la Regencia, plaza de cadetes, en el Real

24 Cókdova, $I b ., 1,2,14,16-18,29$.

25 CóRdova, $I b ., \mathrm{I}, 19$.

26 Córdova, $l b ., 1,19-20$. 
cuerpo de Guardias Españolas, pasando a Madrid, a su acreditada Academia, donde se recibía una excelente educación militar, y pagando sus asistencias con la legítima correspondiente a la fortuna que nos correspondió por muerte de mi abuelo el general"27.

\subsection{Un suceso que cambió una vivencia}

En su relato pronto trasporta su hermano Fernando a Luis a Cádiz entre 1819 y $1820^{28}$ : "Contaba apenas mi hermano entonces veintiún años; acababa de ser nombrado por S.M. oficial de Guardias Españolas, y destinado a petición propia, al ejército de Uitramar, donde, escuché de sus labios muchas veces, quería vengar la desgraciada muerte de nuestro padre, yendo a combatir contra los enemigos de la patria. Por esta circunstancia encontrábase en Cádiz en aquella fecha, permaneciendo completamente extraño a los manejos y conspiraciones que en aquel ejërcito se fraguaban; pues si bien sus ideas y sentimientos empujábanle hacia la causa liberal, debía personalmente y profesaba ya gratitud y amor a la persona del Rey. Aun recuerdo distintamente el efecto que en él produjo la noticia de lo acaecido en las Cabezas, noticia que no se esparció en Cádiz hasta el 3 de Enero [de 1820]. Hallábase aquel día enfermo en cama, cuando el movimiento y la agitación de la ciudad anunciaron a sus habitantes lo extraordinario del suceso. No sin que mi madre tratara de impedírselo, vistió el apenas estrenado uniforme de Estado Mayor y salió apresuradamente, anunciando que iba a presentarse a las autoridades para cumplir con su deber".

A fin de comprender aquel pronunciamiento de Rafael de Riego, se impone una previa reflexión: prescindiendo de la política de la primera etapa absolutista de Fernando VII a partir del 4-V-1814 —en los cinco ministerios clásicos las treinta y una situaciones diferentes en sus carteras ministeriales-, se produjo una malestar en el ejército: con el restablecimiento de las pruebas de nobleza para los cadetes de artillería (17-VI-1814) se restauraba la estructura estamental, sin tener en cuenta que en la lucha contra los napoleónicos una parte de los mandos había adquirido sus entorchados por su talento y valor en el campo de batalla. Así se creó una típica tensión entre los militares de carrera y los procedentes del tal lucha. Resultaba evidente la postergación que experimentaron los generales de la guerra ante la reaparición de la oficialidad superior del Antíguo Régimen: oídos sordos a la campanada del reloj de la historia que con su discurso inaugural Diego Muñoz Torrero dio (24-IX-1810) en las

27 Cóndova, $I b ., 1,20-21$.

La América y la España Contemporánea Hispania Sacra 49 (1997) 
Cortes gaditanas: el siglo XVIII había concluído. Situación castrense que el general Girón describe epistolarmente a su padre (concretamente 8-VI y 30VIII-1814): "De los pocos militares que andan alrededor del rey, tenemos el disgusto de que son gente que conoce mejor los paseos de Ceuta y Cádiz que los campos donde se ha reconquistado la independencia española: la estructura del ejército, repleto de generales surgidos en el campo de batalla y relegados ante los antiguos jefes que la paz devolvía a los puestos de relieve."

El "pronunciamiento" - fenómeno y término nuevo- se convertirá (en Espoz y Mina en mayo de 1814, Juan Díaz Porlier en julio del mismo 1814, Luis Lacy en 1817, Vidal en 1819) en la forma específica de combatir un sistema político: el hecho de recurrir al ejército para resolver una divergencia política no es, en definitiva, sino el reflejo social que sufría el país: crisis que en las fuerzas armadas alcanzaba su máxima tensión de resultas de tal choque entre los representantes del orden estamental y los que habiendo ganado sus galones en la guerra trataban de hacer saltar la rígida estructura anterior del ejército. La existencia de una alta oficialidad de extracción nobiliaria aparecía como un obstáculo a las nuevas promociones de militares jóvenes, muchos de los cuales habían alcanzado los más altos empleos. El descontento interno no podía hallar una solución limitada al ejército. Únicamente la sustitución de todo el sistema social podía devolver a los militares sin linaje sus posibilidades de ocupar puestos de primera importancia. De aquí la extraordinaria permeabilidad del ejército a las ideas liberales. Acabamos de mencionar la frecuencia -el pronunciamiento se repite en ocasiones en el mismo año-, que revela la profundidad de ese descontento de ciertas capas sociales: el descontento de la burguesía y del nuevo ejército, realidad indiscutible, encuentra su manifestación externa en estas aisladas y románticas explosiones: la debilidad del pronunciamiento tiene su pareja en la paralela carencia de solidez del Estado que combate.

Y la concentración del ejército expedicionario en las cercanías de Cádiz donde para vengar la muerte de su padre milita voluntariamente Luis Fernández de Córdova - creó una oportunidad favorable para intentar un nuevo pronunciamiento, que se esperaba contaría con el apoyo de las tropas destinadas a América: el real decreto de 9-V-1815 ordenaba la reunión de un cuerpo de 20.000 infantes y 1.500 jinetes junto con la artillería correspondiente, sin que se llegase a reunir tal cifra; el mando del ejército expedicionario había sido confiado al conde de La Bisbal, Enrique O'Donnell. Y, según las Memorias de Santillán, apenas se hallaba algún que otro individuo que no fuera allí destinado de una manera violenta o poco menos. Aunque el señalamiento de los cuerpos parecía haberse hecho por sorteo, nadie dudaba de que había tenido en él más parte la parcialidad que la suerte. En la infantería había bastante número de jefes y oficiales a quienes se concedió ascenso a condición de quedar nulo si no 
se embarcaban. Y no tenían más recurso que marchar o pedir su retiro. Por lo que los jefes y oficiales de regimientos se renovaron cuatro o cinco veces.

Mas el capitán general de Cádiz, Francisco Hidalgo de Cisneros, informó sobre el estado de los barcos rusos que se habían adquirido para el transporte de dicha expedición, declarando que todos ellos eran inútiles.

Conviene añadir la transformación de la masonería dieciochesca - de imprecisas concepciones filosóficorreligiosas- en la del siglo XIX: la decimonónica se caracterizaba por la politización como un simple centro de reunión para conspiradores liberales. Conspiración y masonería se convierten en términos sinónimos, perdiendo sus conceptos de la centuria precedente. El carácter secreto de la institución masónica ofrecía una organización ya constituída para los liberales, que sueñan con restaurar la Constitución de 1812: se hacen masones para conspirar. Es la última forma de acción política que les queda. Mas sus móviles y fines nada tienen de oculto ni de misterioso. Su único anhelo es pronunciarse, o declarar públicamente su fidelidad a dicha Constitución. La conspiración urdida en reuniones secretas, tenebrosas sólo para la imaginación romántica, tiende siempre a realizar el acto público de pronunciarse en favor de la fórmula política ya conocida: la Constitución de Cádiz.

Antonio Alcalá Galiano (1789-1865) -n Recuerdos de un ancianodescribe los trabajos masónicos de "Soberano Capítulo" - "Cuerpo supremo y misterioso", director del movimiento del ejército expedicionario, "que celebraba sus sesiones sin aparato ni fórmula en la casa de Francisco Javier Istúriz" (Cádiz, 1790, + Madrid 1871) - y "Taller Sublime" (con Mendizábal). Utilizaba como medio de acción las logias que constituían sociedades de grado inferior, extendidas hasta el nivel de regimiento, cuyo simbolismo "no impedía ver claro el fin que se caminaba". Mas la "traición del Palmar", perpetrada por . el conde de La Bisbal y su segundo el irlandés Pedro Sarsfield $(+1837$ en Pamplona), desarticuló la conspiración, si bien el gobierno fernandino separó a éstos del mando (con la recompensa de la gran cruz de Carlos III y con el empleo de teniente general, respectivamente). Se asignó en su lugar (8-VII-1819) el mando al conde de Calderón, que tendría como inmediatos colaboradores a los mariscales de campo Estanislao Sánchez Salvador y Francisco Ferraz. Pero el 13 de aquel julio Alcalá Galiano podía reunirse con unos cuantos de sus amigos para continuar acerca de los medios de proseguir la empresa, a la que las prisiones del brigadier O'Daly, los coroneles Antonio Quiroga, Rotén y Arco Agüero, y el comandante Evaristo San Miguel, no habían restado gran fuerza; y tres días después se reunía con Antonio de la Vega y Juan Álvarez Mendizábal. Este se ofreció atender a las necesidades económicas de la empresa, pues en función de proveedor del ejército tenía amplia libertad de movimientos. Tras una epidemia, Alcalá Galiano dejó Cádiz (20-XI-1819) hacia 
Alcalá de los Gazules, donde se hallaba preso Quiroga, con el fin de convencerle para asumir el mando de tal empresa ante la falta de un oficial general; y aceptó. Mientras Alcalá Galiano proponía a diferentes unidades militares el nuevo jefe, Mendizábal lo hacía por su cuenta, entrando en contacto con tropas de diversos cantones, entre las cuales se hallaba Rafael del Riego y Núñez (+ 7-XI-1823) en Cabezas de San Juan, fijándose el plan elaborado por Riego en la noche del 27 al 28 de aquel diciembre. Y así en la mañana del primer día del nuevo año (1820), Riego, puesto al frente de sus hombres, proclamó la Constitución con la lectura de un manifiesto de Alcalá Galiano y emprendió la marcha hacia Arcos de la Frontera y Jerez. Mas Quiroga falló con su plan en Cádiz ante la presencia de Luis Fernández de Córdova, si bien Riego se reunía con Quiroga el 7 de enero en la Isla de León o San Fernando ${ }^{29}$.

Según recordaba Alcalá Galiano, "al saberse [en Cádiz] confusamente lo que había ocurrido en Arcos, donde había caído prisionero el general del ejército expedicionario, y con alguna más claridad que habían entrado en la Isla de León tropas de los levantados, las autoridades de la plaza de Cádiz trataron de defenderla. El Teniente de Rey [Rodríguez Valdés] acudió al general Campana, el cual tomó el mando con cualquier título [...]. En esto un joven animoso tomó a su cargo la defensa de la Cortadura. Era el de quien ahora hablo, el capitán de infantería D. Luis Fernández de Córdova [...], entonces de pocos años y ningún renombre, no obstante lo ilustre de su familia. Tenía yo relaciones de parentesco con Córdova y alguna amistad, y bien podría, si hubiese yo andado libre por Cádiz, haber tratado de atraetlo a nuestro partido, y es probable que lo hubiera hecho, y aún que lo hubiera conseguido, porque no tenía él opiniones políticas formadas, y de su carácter podía presumirse que lo sedujesen el atractivo de la llamada libertad y una empresa que abría a su actividad un camino ancho y, según la opinión de muchos en aquellos días, glorioso. Pero Córdova sólo supo que había una rebelión o sedición militar, y que faltaban fuerzas para hacerle resistencia, si bien no tanto que algo no pudiese hacerse, y este poco cubriría de gloria a quien con brío lo acometiese, mayormente si, favoreciéndole la fortuna, salía airoso de su empeño. Marchó, pues, a la Cortadura, con poquísima gente - 48 según apostilla su hermano Fernando F. de Córdova-- de la Milicia urbana y algunos artilleros; llegó allí por su buena suerte, y nuestra desdicha, y la tardanza de Quiroga, como una hora antes de los que venían a ocupar aquel puesto se presentasen; al sentirlos venir, dio voces, armó alborotos, aparentando tener consigo gran fuerza, mandó hacer disparos con tanta felicidad, que de dos cañonazos - añade Fernando F. de Córdova: «como no se encontrara mecha para inflamar la carga [...], aplicóles su cigarro"- uno hizo estragos en el enemigo, y con osadía y habilidad,

29 ARTOLA, $I b ., 552,561-562,614,616-617,619,634-639,642$.

La América y la España Contemporánea Hispania Sacra 49 (1997) 
cuando ya pocos, si acaso algún mal disparo podía hacer, vio retirarse a los que venían a apoderarse del punto de cuya defensa se había encargado, labrando con este hecho la fábrica de su fortuna, que después tuvo su mayor aumento en una causa, si no idéntica, análoga a la que él había sido ardoroso contrario" (por fidelidad a la hija de Fernando VII, como presenta su hermano Femando ${ }^{30}$ ).

Entretanto, en Cádiz el general José Álvarez Campana creaba un batallón de "Leales a Fernando VII", quienes rescataban a dicho general y al gobernador Rodríguez Valdés, presos por una conjura gaditana, si bien pudo escapar hacia la Isla el coronel Santiago Rolande. Mientras, Francisco Javier Cienfuegos Jovellanos, obispo de Cádiz-Ceuta (4-VI-1819 hasta 20-XII-1824, en que pasó al arzobispo de Sevilla, cardenal 3-III-1826, desterrado en Alicante 18-II$1836,+21$-VII-1847), publicaba una carta pastoral (7-I-1820) con una profusión de citas del Antíguo Testamento y de ejemplos de la Antigüedad, para concluir en el carácter religioso de la obediencia al príncipe por su condición de "instituido por Dios": tampóco había oído la campana del reloj de la historia. Fue contestado por otro escrito de Evaristo San Miguel, firmado por Antonio Quiroga, rebatiéndole las acusaciones contra los pronunciados. Y ante los alzamientos liberales de Oviedo, Murcia, Cartagena, Zaragoza, Barcelona, etc., sin derramamiento de sangre (excepto en Cádiz) Fernando VII juraba la Constitución de 1812 (7-III-1820).

Previamente, en el mismo Cádiz, el capitán de navío José Primo de Rivera (padrino de bautismo de su sobrino el futuro cardenal Fernando de la Puente y Primo de Rivera, 29-VIII-1808, nacido el día anterior), quien tenía a su cargo el mando de la Cortadura (desde el 4-I-1820), se presentó al capitán general de la armada, Villavicencio, exponiéndole que "tenía muchos gallegos en la escuadra y desconfiaba de su oposición al pronunciamiento". El general Manuel Freyre pasó a Cádiz (9-III-1820), se presentó al propio Villavicencio, quien le informó que una parte de la escuadra y tres batallones de la guarnición se habían declarado favorables a la restauración constitucional. Con la llegada de Antonio Alcalá Galiano, Arco Agüero y López Baños como parlamentarios (10-III-1820), los ánimos se encresparon, Freyre huyó, Villavicencio se embarcó en el Numancia, y Riego entraba en Cádiz (2-IV-1820) con Quiroga (dos días después) $)^{31}$.

"Mi hermano [Luis] —relata Fernando F. de Córdova"32 — salió de Cádiz para incorporarse en Madrid a su regimiento, si bien tuvo al poco tiempo que abandonar la capital por virtud de la causa que se formaba con motivo de los acontecimientos del 10 de marzo en Cádiz, de la que no resultó ningún cargo

30 Córdova, Ib., I, 23-24, 34, 129.

3] ARTOLA, Ib., 644-664.

32 Córdova, $I b$, I, 28-29, 42.44, 46-47.

La América y la España Contemporánea

Hispania Sacra 49 (1997) 
[...]. Meses más tarde, encontrándose en Sevilla, obligado a permanecer en aquella ciudad, en virtud de los procedimientos que se le seguían por los sucesos de Cádiz, debió una noche en el teatro de pasar, para sentarse en su luneta, cerca de uno de los oficiales del ejército liberal, que [...] [le] insultó, y la reparación pedida en el acto. Al siguiente día, en efecto, verificábase el duelo, cayendo el oficial atravesado de una estocada [...]. [Ya en su Regimiento de la Guardia participó en] la célebre e infortunada acción del 7 de Julio [de 1822] [...]: en la noche del 5, mi hermano Luis, comisionado por todo el cuerpo de oficiales, salió del Pardo y penetró secretamente en el Palacio, celebrando con Fernando VII una conferencia de tres horas, presenciada únicamente por el Duque de Alagón y el Conde de la Puebla del Maestre, sumiller de Corps [...]. Verificada después aquella desastrosa retirada [...], muchos oficiales, y entre ellos mis dos hermanos (José y Luis), encontraron seguro refugio en las habitaciones de la Casa de Campo [...] cerca de la familia Real, un asilo [...]. De mi hermano Luis sé decir que, más comprometido que todos y amparado por el Rey, que le proveyó de dinero en cantidad respetable, hubo a poco de ganar la frontera francesa [...]. Y en el [año] de 1823 ocurrió la invasión de los «cien mil hijos de San Luis», con cuyo ejército, al que se unieron dos batallones formados con los soldados y oficiales de la Guardia derrotados en la jornada del 7 de Julio, y la Regencia, vinieron mis hermanos, haciendo su entrada en Madrid [...], reunida toda mi familia".

\section{ACTIVIDAD PASTORAL DE PUENTE EN UN AMBIENTE DIFÍCIL}

\subsection{Fernando de la Puente entre dos situaciones sociales.}

Fernando Agustín Santiago de la Puente y Primo de Rivera: así quedó registrado en la partida sacramental de bautismos (libro 4, folio $312, n^{\circ} 2374$ ) de la parroquia gaditana de San Antonio, bajo el padrinazgo del citado capitán de navío (entonces aún de fragata) José Primo de Rivera, que expuso al capitán general de la armada, Villavicencio, la situación levantisca de una gran parte de la fuerza militar que se hallaba bajo su mando. Sin embargo, los padres del ahijado (Bemardo y María del Pilar) habían fallecido cuando éste sólo contaba doce años. Los biógrafos y panegiristas del futuro cardenal Puente, sin referirse a sus otros seis hermanos, le trasladan al colegio de Santhberto de Durham, al norte de Inglaterra - por medio de una tía suya, encargada de su educación-. Allí se formaban los hijos nobles de las familias católicas de aquella nación; entre ellos se anota al también futuro cardenal Nicholas Patrich Wisseman (Sevilla 1802, + Westminster 1865), con quien le unirá larga y es- 
trecha amistad hasta que éste abandone su ciudad natal hispalense el 9-III1845. En dicho colegio inglés estudió lenguas, matemáticas, literatura, tal vez filosofía, "hasta que un revés de fortuna, que no era fácil prever, le hizo volver a España para continuar su carrera en la célebre Universidad de Sevilla" ${ }^{133}$. Y una nube histórica oscurece su partida y regreso a la patria, en tomo a si fue testigo de la reimplantación de la Constitución de 1812 en Cádiz aquel 2-IV1820 con su padrino, o si vivió el Trienio liberal o la década absolutista ${ }^{34}$.

Tras el fallecimiento de la tercera esposa de Fernando VII, María Josefa Amalia de Sajonia (mayo de 1829), éste volvió a contraer nupcias (9-XII1929) con María Cristina de Borbón y Dos Sicílias, hija del rey de Nápoles. Ese matrimonio se realizaba dentro de un ambiente espectante de "traer novedades deseadas que no podían esperarse de D. Carlos", hermano del rey, según el comentario de Fernando F. de Córdova ${ }^{35}$, que siendo oficial de la Guardia "le cupo el honor de bailar" con la nueva reina en la recepción de bienvenida que a su llegada Barcelona le deparó, y luego luchó contra los carlistas; y, sin embargo, ante la sugerencia de José Fulgosio, comisionado por la esposa de Don Carlos, Francisca, para invitarle a pasarse a su bando, confiesa que "sin su hermano Luis y sin la recomendación de Fernando VII, yo hubiera sido carlista; a esta bandera me conducían entonces mis simpatías personales por aquella rama de la familia Real".

Antes del nacimiento de su primogénita Isabel (10-X-1830), Fernando VII promulgó (29-III-1830) la Pragmática Sanción que su padre Carlos IV (17481819) había aprobado en las Cortes generales de Madrid (septiembre de 1789) para la jura y proclamación del príncipe Femando como heredero del trono: abolía la Ley Sálica, implantada por su abuelo Felipe V en 1713 (privando a las mujeres del derecho de sucesión al trono), si bien se abstuvo de publicarla. Mas como dichas Cortes se comprometieron a guardar el secreto, quedó --ante el juicio público - subsistente la validez de tal Ley Sálica, dando lugar a la presentación de los derechos de Don Carlos (28-III-1788, + 10-III-1855); derechos adquiridos, pues había ya nacido antes de dicha aprobación en 1789.

Muchos sacerdotes, según Cárcel Ortí36, dudaron de la obligatoriedad de mencionar a la heredera en la oración Et fámulos, que por privilegio de los papas San Pío V (1566-1572) y Gregorio XIII (1572-1585) se recitaba en las

33 M. ALBJACH, El Cardenal Puente, antecedente de nuestra Facultad: "Burgense" 37/1 (1996) notas 3-7.

34 ARTOLA, $l b, 671-947$. REVUELTA, $l b, 84-113$.

3 Córdova, $l b$., I, $114,134,163-166,248$. F. BastarReChEA-CePeda-Martinez Ruíz, $l b$., 548 , nota 8.

36 Vicente CARCEL ORTí, El liberalismo en el poder (1833-68). Historia de la Iglesia en España. B.A.C., Madrid 1979, t.V, p.118-119.

La América y la España Contemporánea

Hispania Sacra 49 (1997) 
misas. Algún obispo fue acusado de negligencia, y el primer ministro y encargado de la cartera de Gracia y Justicia, Francisco Tadeo Calomarde (17731842), urgió el cumplimiento de dicha norma. Además el propio Fernando VII se quejó al papa Gregorio XVI (1831-1846) de que muchos clérigos hubieren adoptado actitudes abiertamente beligerantes y pidió que les exhortase a la obediencia y a la paz, y Gregorio XVI dirigí una carta encíclica (7-III-1833) a los obispos españoles.

Ya se habían producido los levantamientos del general Bessières (fusilado por el general conde de España) y los de Barcelona y Zaragoza ${ }^{37}$. También "los sucesos de La Granja", con ocasión de la enfermedad de Fernando VII (13-IX-1832), recuperado desde el 21 de aquel septiembre y la presencia de la infanta Luísa Carlota, esposa de Francisco de Paula y hermana de la reina, produciéndose la crisis total del gobiemo, que presidió Francisco Cea Bermú$\operatorname{dez}(1779-1850)$ el 1-X-1832, y ofreciendo un indulto general para liberales y afrancesados $(7-\mathrm{X}-1832)^{38}$. Fernando VII autorizó a su hermano Don Carlos para acompañar a la princesa de Beira a Portugal, una fórmula de destierro pues encargaba su vigilancia al embajador en el país luso Luis Fernández de Cordova $^{39}$. Muerto Fernando VII (29-IX-1833), proliferaron las sublevaciones carlistas con Manuel González (3-X-1833) en Talavera de la Reina; en Bilbao, el marqués de Valdespina, Zabala, Bengoechea y Latorre; en Vitoria, Berástegui y Uranga; en Burgos el cura Merino; y en Navarra y La Rioja, Santos Ladrón. A pesar de los primeros triunfos liberales del general nacido en Irlanda Pedro Sarsfield (+ 1837 Pamplona) en Vitoria y Bilbao, los carlista reaccionan, iniciándose la guerra que acabará con el "abrazo de Vergara". (3I-VIII-1839) entre los generales Espartero y Maroto ${ }^{40}$.

$\mathrm{Y}$ en este ambiente de guerra carlista aparecen los primeros datos de Fernando de la Puente en Sevilla: queda registrado su empadronamiento sevillano (19-XII-1831), en la calle Trajano número 14, en la parroquia de San Andrés, a la vez que el certificado, refrendado por el rector de la Universidad, Francisco de Paula Cerezo, sobre "estar suficientemente instruído para pasar a estudiar filosofía", con una somera descripción --"de edad de veintitrés años, color trigueño claro, ojos pardos, pelo castaño"- (21-XII-1831); mas, por otra parte, hay constancia de sus estudios de filosofía desde 1830 a 1833 . Y en este último año inícia la teología, apareciendo - según el expediente 212-18 del

\footnotetext{
37 CóRdova, $1 b ., \mathrm{I}, 60,96-99$.

38 M. ALBIACH, Religiosidad..., 505-506.

39 CórdovA, Ib., I, 130-135, 141-145.

40 Julio ARÓSTEGUI SÁNCHEZ, El carlismo y la guerra civil. La era isabelina y el sexenio revolucionario (I834-1874), Historia de España, Espasa Calpe S.A., Madrid 1988, 2." ed., t. XXXIV, p. 71-139: Córdova, Ib., I, 145-405; II, 2-155.
} 
Archivo-Biblioteca de la universidad sevillana (Alumnos) - un expediente (1VII-1834) que firma como presbítero, sin constar ni en la nota marginal de su partida de bautismo ni en nuestra gestión realizada cabe la curia eclesiástica hispalense la fecha de su ordenación sacerdotal. Su sacerdocio, pues, se desenvuelve en un ambiente religiosamente enrarecido y se le verá participando en la guerra carlista y en otros sucesos análogos.

\subsection{En los albores de una nueva sociedad española.}

Tras el fallecimiento de Fernando VII, alborea una nueva sociedad: la reina María Cristina quedó como gobemadora del reino durante la menor edad de su hija Isabel II, mas la actitud de la Santa Sede ya no fue la misma ${ }^{41}$, aun conservando a Cea como jefe del gabinete ministerial, pese a las presiones de embajadores (francés, Rayneval, e inglés, Williers), militares (como Luis Fernández de Córdova) ${ }^{42}$ y eclesiásticos (por el reglamento de imprenta (4-I-1834), protestado por los prelados de Orihuela (Herrero Valverde) y de Tarragona (Echánove) $)^{43}$.

Hubo de ceder el poder a Francisco Martínez de la Rosa (1778-1862), quien compuso (15-I-1834) un gobierno con antiguos afrancesados como Francisco Javier de Burgos (1778-1849) y el jurisconsulto Nicolás $M^{2}$ Garelli (Valencia 1777 - Madrid 1850) -estos tres compusieron el Estatuto Real ${ }^{44}$ en su mayor parte (10-IV-1834).

El ministro de Gracia y Justicia, el citado Garelli, dirigió una circular (a finales de enero de aquel 1834) a los obispos y superiores religiosos para que tomasen medidas enérgicas con el fin de que "ni en el púlpito ni en el confesonario se extravíe la opinión de los fieles, ni se enerve el sagrado precepto de la obediencia y cordial sumisión al legítimo gobierno de S.M., que tan encarecidamente recomiendan las leyes divinas y humanas"; también se entrevistó con el cardenal Tiberi (1773-1839), nuncio (1827-1833) y entonces pronuncio (ante el rechazo del nuevo nuncio Luigi Amat (1796-1878) a quien Gregorio XVI no concedió credenciales ante Isabel II, y tuvo que marchar de España a primeros de septiembre de 1835), para comunicarle la necesidad que sentía el gobiemo de tomar algunas medidas sobre los bienes y conducta del clero. Mas Garelli unilaterlmente prohibió la provisión de prebendas (excepto las que llevaban aneja cura de almas, las de oficio y las dignidades con presencia en

4 M. ALBIACH, Religiosidad..., 505-506.

42 Joaquin TOMÁS VILLAROYA, El proceso constitucional 1834-1843, La era isabelina y el sexenio democrático (1834-1878), Histotia de España, Espasa Calpe S.A., Madrid 1988, 2." ed., t. XXXIV, p. 6.

43 CARCEL, El liberalismo..., 130.

44 VILlaRRoYA, $I b ., 8$.

La Amética y la Espafia Contemporánea Hispania Sacra 49 (1997) 
los cabildos) para aplicar dichas rentas a la extinción de la deuda pública (9III-1834), creó el Tribunal Supremo de España e Indias con conocimiento de los asuntos contenciosos del Real Patronato y los recursos de fuerza de la Nunciatura Apostólica (24-III-1834), ocupó las temporalidades de los eclesiásticos que abandonando sus iglesias se unían a los carlistas y emigraban del reino sin licencia de la autoridad civil (26-III-1834), suprimió monasterios y conventos de donde algún fraile hubiese escapado para unirse a los carlistas (26-III-1834), llamó a entrar en quintas a los novicios de las ordenes religiosas, y trasladó a los religiosos de los conventos suprimidos (10-IV-1834).

Con el pretexto de haber envenenado las aguas potables y, según la creencia de aquella época, produciéndose una epidemia de cólera, el pueblo madrileño asesinó a cuatro jesuitas y hasta cerca de un centenar de otros religiosos (franciscanos, carmelitas y dominicos) (15-VII-1834) ${ }^{45}$.

El episcopólogo burgalés Manuel Martínez Sanz, al describir el pontificado de Ignacio Rives Mayor (1832-1840), lo 'califica de "poco tranquilo" por la guerra carlista, y a su muerte actuó como Administrador Apostólico (por Breve pontificio de 6-IV-1845) el prelado de Pamplona Severo Andriani hasta la llegada de Cirilo Alameda Brea (1849-1857), inmediato antecesor de Fernando de la Puente ${ }^{46}$.

Mientras, el gabinete de Martínez de la Rosa había sido sustituído por el conde de Toreno (1786-1843) el 7-VI-1835; éste, al frente del primer gobierno del Estatuto Real, presentó con su ministro de Hacienda, Mendizábal, en el estamento de procuradores los presupuestos de gastos e ingresos de $1835^{47}$.

Fernando de la Puente proseguía sus estudios universitarios hispalenses de teología, que - ante la guerra carlista-, como ya insinuamos, hubo de interTumpir, al ser movilizado por la "Quinta de Mendizábal" o de los "Cien Mil". Pero antes, consideremos el siguiente precedente, entresacado de la correspondencia personal de Mendizábal y Luis Femández de Córdova: como vimos, ya se habían enfrentado en el descrito pronunciamiento de Riego en 1820. Enfrentamiento, cuyas secuelas tratan vanamente de superar los dos protagonistas, e incluso el embajador inglés Williers ${ }^{48}$. Mendizábal, que no había aceptado ningún premio ni cargo oficial durante el Trienio liberal, no obstante emigró a Inglaterra. Allí hizo fortuna y estableció una importante casa comercial en Londres. En julio de 1830 la burguesía francesa había destronado a Carlos

45 CARCEL, El liberalismo..., 131-134.

45 Boletín Eclesiástico del Arzobispado de Burgos (BEAB) XVII (27-X-1874) 202-204. Cf. Angel Gonzalo Gozalo, El Cabildo Catedral de Burgos en el siglo XIX (1808-1902), Andalucía Graficica, Baena 1993, 328-335.

47 VILLARROYA, $l b ., 23$.

48 CóRdova, Ib., $1,309$. 
$\mathrm{X}$ y proclamado rey al duque de Orleáns; Luis Felipe, al no lograr su inmediato reconocimiento por parte de Fernando VII, utilizó a los emigrados españoles para forzar la voluntad de Fernando permitiéndoles concentrarse en la frontera pirenaica con apoyo a sus intentos de invasión; Mendizábal se puso en contacto con el banquero Ardoin (en agosto del mismo 1830) para sufragar los gastos de tal invasión, como agente financiero, cuya influencia resultaba decisiva; mas el reconocimiento de Luis Felipe por parte del monarca español dificultó la expedición, desde el momento en que Femando. VII exigió del rey francés la disolución de los grupos armados a lo largo de la frontera y el internamiento de los emigrados, por lo que el gabinete galo expidió órdenes para desarmar a los españoles, si bien el coronel Valdés emprendió una marcha que fracasó ${ }^{49}$.

Sin embargo, dada la buena posición del entomo económico de Mendizábal, el emperador del Brasil, Pedro I (1798-1834), le encargó la negociación de créditos y garantizó el préstamo para restablecer en el trono portugués a su hija María de la Gloria II (1819-1853), misión que Mendizábal realizó con total éxito en 1833, lo que llevó a la reina lusa a nombrarle primer ministro, y al ya citado conde de Toreno su ministro de Hacienda en 1835: capaz de salvar a nuestro país del caos hacendístico y revolucionario: "Se ha colocado en la actitud de un piloto temerario a quien la fuerza de la tempestad y el peligro del navío hubieran inspirado sentimientos de prudencia. Ha visto a mucha gente en estos días; ha consultado por todas partes la opinión pública, y se ha convencido de que su unión con Toreno es completamente imposible. Se perdería él sin utilidad para nadie. Ayer estuvo en el Sitio [con la Reina Gobernadora] [...]. Si la Reina le rechaza y Mendizábal se aleja, me temo - escribe el mencionado embajador inglés Williers a Córdova (10-IX-1835) sión general contra el Ministerio y aun contra S.M. [...]. Ayer me entregó la carta adjunta, rogándome que se la enviara y le dijese que va escrita con todo el corazón. Entonces fue cuando le dije todo lo que V. me escribía en su última respecto de su porvenir y de su misión en estos momentos - como general en jefe del ejército liberal del Norte contra los carlistas tras la victoria de Mendigorría (16-VII-1835) ${ }^{51}$ - y de las esperanzas que podían fundarse en un Ministerio o en una situación presidida por él. Ha quedado ARCHICONTENTO: no puede V. verdaderamente figurarse la alegría que aquello le causo".

Y en la carta que el propio Mendizábal enviaba (desde Madrid 8-IX-1835) al general Córdova se expresaba así: "Querido amigo: Al dirigir a V. estas cuatro letras, séame permitido, que le trate con preferencia con el título de

49 ARTOLA, $I b, 912-914$.

so CóRDOVA, $l b$., I, 309-310.

51 ARÓSTEGUI, $l b$., 114-115. 
amigo. Nacidos en un mismo suelo, conocidos antiguos (en el pronunciamiento de Riego, o antes quizás) y embarcados con gloria en una misma causa, me lisonjeo que V. pensara como yo, que debemos ser amigos. Aun no me he encargado del Ministerio: es preciso no sólo discurrir los medios de salvarnos, sino convencer a las personas que deben contribuir a hacer la aplicación, que ellos son los mejores, o a lo menos, los menos malos. ¡Esto es más difícil que lo demás! Deseo a V. mucha felicidad, y que disponga de su paisano y amigo que su mano besa. J.A. Mendizábal"s2.

Los acontecimientos se precipitaron, y el esposo de la Reina, Fernando Muñoz, escribía (desde El Pardo, 20-IX-1835) al general Córdova: "Mi apreciable dueño y amigo: S.M. me manda dar a V. las gracias por su carta que ha leído a Mendizábal [...]. Ya habrá V. sabido que se apartó a Toreno [14-IX1835] de los negocios, y demás cosas con respecto a esta mudanza [...]. S.M. sentó el principio «de que era preciso conceder al pueblo aquellas cosas justas y que reclamasen las circunstancias, antes de que la opinión general las arrancase al Trono, en cuyo caso perdían su virtud» [...]. ¡Dios nos saque en paz de esta lamentable situación! [...]. Adiós, mi buen amigo [...]. Este su afectísimo amigo, que lo saluda con el más alto respeto, y desea ocasiones en qué poderlo complacer y b.s.m.- Femando Muñoz"s3.

Nueva carta de Mendizábal a Córdova: "Madrid, 29 de Septiembre de 1835: Querido amigo y paisano: Escribí a V. ayer, y lo repito hoy, para mandarle los adjuntos decretos de la convocatoria de Cortes, medida con que creo conciliar los ánimos, y se conciliarán, a pesar de que en Cádiz piden cosas que no son admisibles: ¡disparates, locuras! Mas confio, sin embargo, en que la razón y la aquiescencia de casi todas las províncias rectificarán ciertos desacuerdos. Siéntolo sólo, porque no me dejan ancho campo para poder sacar de él todos los medios, y acabar con esa guerra que debe ser nuestra atención preferente. A pesar de todo, saltaremos vallas, venceremos cuantas dificultades se presenten, y con nuestros recursos y los que nuestros aliados nos proporcionen, veremos pronto concluída esa guerra devastadora [...]. Cuente V. conmigo para todo [...] como servidor y amigo [...]. Suyo- J.A. Mendizábal"54.

Mendizábal sometió a muchas de las juntas revolucionarias, que ilegalmente se hallaban establecidas en las províncias; entre éstas la de su ciudad natal Cádiz, una de las que más tiempo tardaron en reconocer la autoridad del primer ministro, el cual tuvo que transigir al convertirlas en Diputaciones provinciales, encargadas del armamento y defensa de sus territorios respectivos contra los carlistas. Asumió el propio Mendizábal en momentos críticos una

52 Córdova, Ib., J, 310. Cf. nota 50.

53 Córdova, $I b ., \mathrm{I}, 314$.

s4 Córdova, Ib., I, 316-317.

La América y la España Contemporánea Hispania Sacra 49 (1997) 
đictadura liberal, salvó por algunos meses de su ruína al país y a las instituciones, y trató de mantener cordialísmas relaciones con su paisano el general Luis F. de Córdova: en enero de 1836 le decías: "Mi querido amigo y paisano: [...] Yo jamás me enfado; es verdad que V. no me da motivos, y aunque me los diera, como más viejo, cedería. ¡Me alegraría que V. me diese motivos, y vería $V$.! Hace cinco días que me decía V. que le servían de consuelo mis cartas, aunque fuesen de dos líneas, y V. ahora me ha escrito oficios muy largos, pero ni una sola línea de amigo [...]. Si lo supiesen nuestros enemigos, que son los de la patria, ; cómo lo celebrarían! [...]. No demos días de gloria a nuestros enemigos". Y el 15 de Enero, contestando a otra del general, relativa a las operaciones que íbamos a emprender sobre Arlabán (17-I-1836) ${ }^{56}$, le escribía: "[...] No haga V. caso si le digo que ataque, etc., etc.; debe hacer lo que quiera, y no hacer caso de la maledicencia. Estoy rendidísimo, sin tiempo para nada, ni aun para estas cuatro líneas. Trabajemos para que aquí se repita la capitulación de Evora-Montes."

"Algunos días después le decía:"[...] Las intrigas redoblan aquí para derribar al Ministerio, más que nunca, a medida que observan aproximarse el momento feliz del triunfo. Sigue remitiéndose dinero al ejército, y continuará. Adelante V. sus trabajos, y si bien en Marzo no recibirá auxilios metálicos, desde luego puede contar en Febrero con cuatro millones más de los anunciados."

El 19 del mismo mes daba con igual vehemencia los interesantes pormenores contenidos en la siguiente carta: "Mi querido amigo y paisano: Me tiene V. lleno de la mayor ansiedad, más por $V$. que por la suerte de la patria, pues conozco la circunspección con que obra $V$.; pero temo su arrojo, y así como yo me cuido más que nunca, lo he hecho, porque una enfermedad perjudicaría mucho, así $\mathrm{V}$. debe cuidarse de una bala perdida. Las intrigas continúan cual nunca, no obstante el triunfo conseguido con el voto de confianza y demás votaciones [...]. He hablado muy largamente con Imaz y voy a hacer un esfuerzo para enviarle en las dos semanas primeras de Febrero hasta la cantidad de 20 millones de reales, contando con lo que V. ha recibido desde el 21 de Diciembre. Además los vestuarios, el arreglo de los hospitales, nada se quedará por hacer para dejarle airoso. Respetando como debo sus planes de V., le ruego me indique en grande lo que se propone operar, para que yo con este conocimiento haga mis combinaciones [...]."

"A fines de aquel mes de Enero, sobre un artículo de la ley electoral en el Estamento de Procuradores [...], dióse el caso, tan frecuente entonces como desconocido ahora [antes de 1883], de que la mayoría derrotase en su votación

5s Córdova, $I b .$, II $, 3-12,16-20,40-53,74-81,122-125$.
s6 Córdova, $I b .$, I, 262-265, 340-364, 404-405.

La América y la España Conternporánea Hispania Sacra 49 (1997) 
al Ministerio que la representaba [...]. «Mi querido amigo y paisano -escribía (Mendizábal) a mi hermano en 26 de Enero: [...] Ya dije a V. que las intrigas se multiplicaban [...]. Jamás Gobierno alguno se manifestó en términos más conciliatorios ni fue tan completamente desairado como me sucede a mí [...]. Me resolví a dejar el Ministerio. Consideraciones de otra especie, súplicas y ruegos de amigos imparciales me han obligado por esta vez a dar la preferencia a la disolución del Estamento y convocatoria de otro por medio de ley emanada del Estatuto Real [...] para consultar la opinión del país en su propio órgano [...]. Aun todavía no está decidida S.M. ni el Consejo de Gobierno; pero ambos me han dicho que todo menos «separarme yo de los negocios». Es indispensable que hagamos desaparecer todo pretexto de desorden y confusión. Como se rompa una vez el dique de la unión, que aun se conserva entre nosotros, no sé adónde iremos a parar [...]. Soy hombre de mucha suerte, y con ella y con mi imparcialidad cuento para el triunfo. Dispense V., mi querido paisano, el que no entre en este momento en tantos detalles como quisiera y debiera, y créame siempre su fiel amigo.»

"Y al día siguiente [...], al publicarse el decreto de disolución, añidía con una pesadumbre evidentemente sincera: «Hoy ha sido el día más amargo de cuantos he pasado y pasaré en esta vida, y su recuerdo será siempre el más triste para mí. A mí solo estaba reservado el tener que cerrar las Cortes por una disolución anticipada. Aunque los resultados sean muy felices, jamás me justificaré. Podré encontrar consuelo en no haber sido yo el que lo ha promovido; por el contrario, el que lo ha querido conciliar todo [...]. Me consolaré también con que este paso ha evitado muchos males». Y el 31 de Enero sobre el mismo asunto: «Todas las noticias que voy recibiendo de las províncias respecto a la disolución de los Estamentos y nueva convocación son muy satisfactorias: en todas partes hacen justicia a la pureza de nuestros sentimientos y de nuestro patriotismo. Si llegamos al 22 de Marzo con orden y tranquilidad y conseguimos una buena elección, habremos adelantado cincuenta años en la carrera política. Las intrigas de toda especie están en juego, y no son pocos los que se dirigen a dividirnos entre V. y el Gobierno, entre V. y el ejército [...]. Estemos nosotros persuadidos de que nuestra amistad es sincera y todas las intrigas se estrellarán en nuestra unión.»

"Grandes debieron ser sus preocupaciones en estos días respecto de la actitud de Córdova para con el Gabinete [...] para mantener la armonía de sus relaciones con mi hermano [...] [para] apelar [...] a haber tenido ambos por cuna una misma ciudad. "No olvide Vd. le decía, lo que más de una vez le tengo recomendado [...]. Tengamos presente a nuestra patria, no olvidemos nuestras glorias, confiando siempre en que la haremos feliz, ia este grandioso objeto debemos sacrificarlo todo, todo, todo! [...]. Firme como una roca, al 
frente de ese ejército, apóyenos V., y viva seguro que en mí encontrará siempre un amigo fiel».

"Al día siguiente continuaba: «Las intrigas se multiplican. Ya le hace a V. [...] entrando en Madrid, ya reñido con el Gobierno [...] que sólo profesa opiniones exageradas [...].» Y en otra, que le retrata bien, añadía: «[...] Para que V. consiga su triunfo, no habrá sacrificio que yo no sea capaz de hacer; mi honor, mi orgullo, mi amor propio, todo está empeñado. Sus glorias, su futura suerte y todo cuanto puede pertenecerle está asociado a mí, como yo estoy asociado a V.; y sus amigos de la niñez, los que en todos tiempos fueron compañeros suyos, las personas más allegadas, no son tan antíguos amigos de $\mathrm{V}$. como yo, así como creo que V. lo es mío [...]. Pensé y hoy deseo, quiero, anhelo y soy avaro de que dos gaditanos sean las dos columnas sobre las cuales se levante este edifício. Si lo conseguimos, habremos hecho un gran bien a nuestra cuna, cuna que fue de la libertad [...], que sólo así podrá ser algo y debe ser mucho.»

"Escribió larguísimas epístolas a mi hermano, de las cuales sólo tomaré los párrafos siguientes: «[...] He auxiliado a V. y le auxiliaré de todos modos: dinero, vestuario, caballos, etc., etc. La guerra de los papeles continúa, particularmente contra el Ministerio, aún más contra mí.» He aquí otra curiosa carta [...]: «Mi querido amigo y paisano: [...] Saldrán pasado mañana 3 millones, y el 10 de Febrero 2.500 .000 y el 20 otros 2.500.000. Después hasta el 15 de Marzo, no cuento con nada positivo. Podrá suceder que le envíe mucho; si puedo, lo haré, no lo dude V. [...]. La tranquilidad existe aquí, me parece que no será perturbada. Me lisonjeo de que reinará en las demás províncias. Si lo conseguimos, habremos ganado para la Europa cincuenta años de edad [...]. Son las cinco de la mañana del 31 (enero 1836), hora de irme a descansar. Abur, amigo mío del corazón.» [...] Veinticuatro horas más tarde le escribía lo siguiente: «V. está muy malo, y yo pienso estarlo de alma y cuerpo [...]. Mientras yo no le veía tan desesperanzado, mi moral no se resentía y marchaba siempre al objeto derecho. Ahora todo ha venido reunido, y principalmente a faltarme la paciencia.»

"Disueltas las Cortes, convocáronse inmediatamente otras, entrando en seguida en el período electoral, con cuya circunstancia arreciaron los trabajos, los desvelos y afanes del Ministerio. En 9 de Febrero prometía, aunque no con la seguridad que suelen hacerlo en estos tiempos (antes de 1883) los Gobiernos, un distrito a mi hermano: ${ }_{\complement}$ Quisiera V. ser elegido Procurador por $C a ́$ diz? - le preguntaba - . Acaba de ocurrirme esta idea. Creo que le lisonjeará, y me parece que no será difícil; por descontado, V. admitirá, pero V. quedará al frente del ejército. De otra manera no sería yo el que fuese a suicidarme. Qui- 
siera extenderme; pero estoy tan agobiado, tan estropeado, que no tengo fuerzas para nada $[\ldots])^{57}$.

\subsection{Nubes en aquel alborear de la sociedad española}

En cambio, "en Palacio no se participaba, ni mucho menos, del entusiasmo que Mendizábal inspiraba todavía a la generalidad del país. Desde El Pardo escribía D. Fernando Muñoz en 23 de Enero al general Córdova: «Mi muy estimado amigo: [...] No crea V. que se complete tan pronto el Ministerio; Mendizábal bien quisiera, pero ¿quién entra con él? y si estuviera $V$. acá, vería si es posible que un hombre que piense, pueda hacer causa suya la del señor Presidente del Consejo de Ministros. En fín, si V. viene, encontrará un mundo nuevo, en el que verá a Mendizábal haciendo el papel de que tíra del cordoncito, para que vean los espectadores los paisajes que otros han pintado [...]. Adiós, mi amigo, deseo ver a V. o recibir sus ordenes para ver de estrechar nuestras relaciones. Cúidese V. mucho, pues de su salud pende la de la patria». Y el 25 le decía también: «[...] Aquí estamos en una crisis bastante seria: el Ministerio ha perdido la votación en un artículo de la ley electoral, que aunque al parecer y aun en su esencia, es de muy poca monta, el Gobiemo lo ha tomado por un desaire y hoy no ha habido Estamento. Mendizábal quiere disolver las Cámaras y reunir ambas Cortes según el Estatuto. Ya ve V. que esto pondrá a S.M. en una posición muy difícil de explicar. Yo creo que en todo debe consultarse al Consejo de Gobiemo. Si tuviera otro Córdova en Madrid, jqué peso se le quitaría de encima a esta Señora, digna de más tranquilidad! [...]. La Reina confía en V. y en su valiente ejército; ansía el feliz día de reunirse a él, ¿y Córdova - dice a menudo- no sabrá tener paciencia para un par de meses que serán los que podrán pasar, para estar al lado de su Reina y de su augusta madre, que compartirán con él los disgustos de la guerra? Espero su contestación con la impaciencia que puede V. imaginarse.» [...]."

"S.M., por su parte, mantenía también una activa, confidencial e interesante correspondencia autógrafa con mi hermano, de la cual puedo elegir los siguientes párrafos para demostrar mi anterior aserto, referente al escaso crédito que en la corte merecía Mendizábal, y la impaciente, resuelta y reservadísima resolución en que estaba S.M. de reemplazarle por Istúriz. En ninguna de las cartas de aquél se deja adivinar que viviera enterado de esta particular circunstancia, mostrándose, por el contrario, confiado y seguro de su preponderancia en el ánimo y en el concepto de la Reina. Tampoco se hallará en la corespondencia de la augusta Señora una sola palabra que induzca a suponer

57 Córdova, $1 b .$, II, 3-12. Cf. nota 55. 
que tuvieran algún fundamento los rumores que afirmaban la posibilidad de un Gabinete presidido por el general Córdova en los comienzos de 1836. Sólo sí se advertirán confirmadas las frases de Muñoz en lo relativo al proyecto de trasladarse la Corte a Burgos o Miranda, para hallarse más cerca del ejército y más inmediata al general que por entonces constituía el principal sostén de las instituciones."

"«Veo que te han engañado - afirmaba S.M. con fecha $1^{\circ}$ de Mayo- diciéndote que yo había tratado con Williers, pues nunca le hablaría de proyectos: está muy unido a Mendizábal, y sírvate esto de regla para todo. A quien he indicado algo y de quien espero, es de Istúriz; él está a favor nuestro y en buenas ideas [...]. Ve con mucho cuidado con los que se hacen amigos, y no será más que para tenerte, si pudieran, entre sus garras.»

"Cuatro días después volvía a escribirle [...]: «[...] Los Procuradores ya ves lo que son y lo que se puede esperar. Hasta ahora los dos proyectos que andan en boga son: el de los unos, a cuya cabeza está Olózaga, de no jurar el Estatuto, y erigirse en Cortes Constituyentes, etc, etc.; el de los otros, y entre ellos Mendizábal, es el de jurar el Estatuto, pero al instante y por medio de representaciones de las Juntas provinciales y petición de las mismas Cortes, revisión del Estatuto, y de aquí lo demás [...]. Adiós; no te escribo más por falta de tiempo [...]. Nadie más sabe de tus compañeros que me escribes y que contesto. Siempre cuenta con tu valor y adhesión, MARIA CRISTINA. »[...]."

"No puede, pues, revelarse más a las claras la enemiga de S.M. hacia su primer Ministro, enemiga que se fundaba únicamente en la desconfianza que debían inspirar su historia y sus ideas ultraliberales, y en los compromisos a que pudiera verse obligado por sus íntimas relaciones con los hombres exaltados y con las sociedades secretas, cuya influencia vemos era entonces poderosísima en España. Para apoyar su política y sus planes que se reducían a sustituir en breve plazo a Mendizábal, necesitaba S.M. contar con la absoluta neutralidad del ejército y con que éste siguiera por la senda que le trazara $D$. Luis de Córdova [...]. No creo yo que estuviera plenamente justificada la desconfianza de la Reina Gobernadora respecto a Mendizábal" —opina Fernando F. de Córdova-.

"Véase últimamente la carta que el 25 de Abril, es decir, en los últimos días de su ministerio, dirigió [Mendizábal] a mi hermano [...]: «Mi querido amigo y paisano: [...] Olvidemos, por un momento, y si podemos para siempre tanto mejor, las intrigas de estos días, nacidas de personas que, considerándose amigas de la nación y nuestras, para lograr sus fines, poco les ha importado sacrificar aquélla y reducimos a nosotros a ser víctimas de sus proyectos [...]. Por mi parte aseguro a $\mathrm{V}$. que desde el día que juré a $\mathrm{V}$. amistad, ha sido, es y será sincera, cualquiera que sea la diferencia de nuestro modo de ver en materias 
políticas [...]. La ambición que tendría hoy sería la de dejar este puesto a otro cualquiera que, fuera cual fuese su suerte, siempre me haría mucho honor [...]. Querido paisano; la mejor y la principal calidad de un hombre de mundo es la de saber esperar. Desde el año 20 esperé, haciéndome superior a todo, y el año de 1835 fui llamado a ser Ministro, retirándome a un rincón en 1836 sin prestarme a ser bandera ni juguete de los caprichos de nadie; de allí volveré a ser sacado más tarde o más temprano [...]. Mis amigos, y los que no lo son porque son neutros, dicen que es indispensable continúe siendo Ministro y que forme un Ministerio que quedará constituído entre hoy y el miércoles, es pasado mañana. En su organización tendré presentes todas sus indicaciones y mi firme propósito de no salir del orden legal; de no transigir con nadie; de desplegar la mayor firmeza dando palos de ciego; progreso legal pero muy racional; cooperación de nuestros aliados cuanta sea necesaria, con el tratado de la Cuádruple Alianza en la mano; medios efectivos para saldar al ejército cuanto se le debe, y satisfacerlo corrientemente para que se establezca la más severa disciplina; recompensar y castigar sin reparar en partidos: he aquí mi profesión de fe; a lo que se debe añadir que al reunirse las Cortes revisoras, todo el poder del mundo no me retendrá treinta y cuatro horas al frente de los negocios. Para que el Gobierno pueda desplegar fuerza y energía, obtener medios, y conseguir la cooperación que sea necesaria, es indispensable que V. y yo, deponiéndolo todo en aras de la patria, nos entendamos, como nos entendimos en Setiembre [sic] y Octubre [...], y por último, que V. y yo nos pongamos de acuerdo [...]: un amigo de quien se repite sinceramente su paisano, J.A. Mendizábal.» «P.D.[...] Según los datos que reúno, no bajará de 10.000 familias las que se interesarán en los bienes nacionales (DESAMORTIZACION) en todo el presente año. Discurra usted alguna recompensa para el soldado al concluirse la guerra.»[...]".

"La contestación que dio mi hermano a esta carta [...]: «Mi estimado amigo y paisano, le decía: ¡Qué difícil es escribir francamente en mi posición y a un Ministro [...], sobre todo cuando éste y aquél no se conocen, cuando han estado toda su vida en filas opuestas y obrando a la cabeza de sus respectivos partidos como enemigos políticos, de lo cual debe seguirse una prevención y desconfianza recíproca y hasta natura!! [...]. Antes de llegar Vd., ni ser nombrado Ministro, tuve un concepto ventajoso de su carácter, pero sobre todo de su capacidad [....]. Con mi hermano no podría contraer liga más sincera y estrecha. Así que apercibí en su marcha de V. grandes errores, nacidos de tantos datos como le faltaban, me dediqué a ilustrar, en cuanto podía, la cuestión militar, base y llave de todas las demás y de las políticas [...]. Ni V., ni sus cartas me daban la menor señal de que las mías eran leídas - ahí están unas y otras, ellas hablen, y júzguelas y con ellas a nosotros un hombre imparcial- $[. .$.$] . Yo$ quise que nos viéramos [...], pues no sabía lo que aquí pasaba [...]; al contrario, 
irritado por las dificultades, apremiado por los ahogos y sucesos, V. me atropellaba y precipitaba, exigiéndome imposibles [...]. ¿Cuál fue mi conducta en estas circunstancias? [...]. Decir a quien estaba obligado a decirlo la la Reina Gobernadora]: «Mendizábal y yo no estamos bien; pero aunque ofendido, y no viendo posibilidad de marchar juntos, Mendizábal es el Ministro de la necesidad, y los males que puede producir su separación, bastarían a hacer forzosa e indispensable su permanencia». Entre tanto trabajaba yo para dejar este puesto directamente, porque [...] mi salud, cada día más arninada, lo exigía [...]. La reforma radical de las órdenes regulares, de la cual soy, no sólo partidario, sino entusiasta - y lo prueba que por mi sola orden tenía yo cerrados más de veinte conventos- entra también en el número, como la venta de bienes nacionales (DESAMORTIZACION), por la que también estoy, sin entender ni examinar la subalterna cuestión del modo [...]; pues lego soy y lego me confieso [...]. Su amistad de V. me fue grata y estoy cierto de que fue sincera algún tiempo, y porque no creo me privaron de ella sino mis enemigos, que por desgracia son los amigos de V. [...]. Y si V. es generoso, no consentiré en que se crea más que yo en este punto, en el que a nadie cedo. En cuanto a Gobiemo y situación, entiendo en todos conceptos, reconciliados o irreconciliables, que V. no puede ni debe ser reemplazado. Esta opinión no es a V. sólo a quien la digo [...]. Declaro solemnemente que no he estado ni estoy en relación directa ni indirecta con los colores ni bandos que pueden considerarse representados por Istúriz o Miraflores [...]. Para hablar con toda franqueza, diré a V. que siento creer que no esté V. bien con la Reina, o que S.M. esté quejosa de V. Esto me parece mal inconveniente, difícil situación, y más debiendo marchar adelante [...]. Yo me ofrezco a ayudarle en lo que pueda y no me sea repugnante, y a no contrariarle ni combatir su persona ni sistema en ningún caso; esto, sea que podamos reconciliarnos o no. De esto tomaré el empeño que $V$. quiera, sin precio ni pacto [...]. Quedo entretanto su afectísimo paisano y servidor Q.S.M.B., Luis Fernández de Córdovas s8.

La destitución de Mendizábal retrasaría los "cincuenta años" que se prometía ante Europa, y tal vez hubiera impedido los movimientos anárquicos posteriores ("sargentada" de La Granja, la "Vicalvarada" y la revolución de 1868) con que finalmente se abriría una nueva sociedad española con sobresaltos y temores, si bien la desamortización no podía ser tan negativa (19-II1836): "en teoría - afirma Cárcel" - la desamortización tenía un planteamiento aceptable, ya que sus objetivos eran fundamentalmente tres: social, económico y político: socialmente se privaría a los antíguos estamentos (clero, nobleza y municipios) de su fuerza económica propia, se prepararía el paso de

s8 CóRDova, $I b$., II, 16-21, 40-53, Cf. nota 55.

s9 CARCEL, El liberalismo..., 138.

Lx America y la Espaffa Contemporánea

Hispania Sacra 49 (1997) 
la vieja sociedad estamental a la nueva sociedad clasista y se dotaría de tierra, mediante la oportuna intervención estatal, a la masa campesina que carecía de ella; la desamortización entrañaba económicamente la posibilidad de cultivar unas tierras que sus antíguos propietarios tenían prácticamente abandonadas; y políticamente el Estado podría llevar adelante sus mediđas revolucionarias, creando una nueva clase de propietarios, interesados en mantener el régimen, porque a su suerte iría unida la de su fortuna personal."

El 15-V-1836 Javier Istúriz (1790-1871), también gaditano, sustituía a Mendizábal, quien exponía a Luis F. de Córdova su planteamiento ${ }^{60}$ al igual que la Reina Gobernadora ${ }^{61}$. Al fin, Istúriz, a fines de julio de aquel 1836 aceptó la postrer dimisión de Córdova: "En este estado, nos sorprendíó la noticia de lo acaecido en la Granja el 15 de Agosto [...]. Hicieron firmar a la Reina, violentamente, el decreto restableciendo la Constitución de 1812 [...]. Seguimos después escoltando [a mi hermano Luis] hasta la frontera [...] y yo me

60 CóRDova, $l b$., II, 74: "He aquí cóma explica aquella importantísima crisis a Córdova el propio Presidente del Consejo de Ministros: "Mi querido amigo y paisano - decía el 15 de Mayo-: Esta será la última que recibirá V. de mí como hombre público; estoy aguardando el decreto de separación de mi Ministerio. Rodil creyó que debía remover los inspectores de milicias, infantería y artillería; S.M. lo rehusó. El Consejo creyó que debía insistir (...), y viendo que no teníamos el derecho de remover ciertas personas, creímos que era legado el momento de dejar nuestros puestos a quienes, mereciendo la confianza de S.M., pudiesen hacer el bien del país, asegurando el Trono y las libertades legales. Como ante todo soy español, no seré de aquellos ministros que harán la oposición por hacerla; muy al contrario, sostendré cualquiera buena medida. El tiempo descubrirá mi carácter (...). No lo dude V., querido anigo y paisano(...). Sin tiempo para măs, se repite suyo afectísimo, Q.S.M.B., J.A. Mendizábal."

${ }_{61}$ CóRdova, $I b$., II, 75, 78-79: "En el mismo correo se dignaba S.M. darle noticia de las razones que le habían impulsado a realizar aquel cambio. Dice así su carta íntegra: "Pardo, 15 de Mayo de 1836: Córdova: Muy deprisa te escribo esta carta para decirte que acabo de mudar el Ministerio, dando la presidencia a Istáriz: las circunstancias lo han exigido: puede ser que este paso parezca precipitado; pero no, ha sido reflexionado por mí y por varios (...). No podia yo nunca acceder a que se mudasen por ahora personas que bien sabía tienen detrás de si a otras que nunca permitiré se me diga se muden (...). Ahora esperemos que ese nuevo Ministerio, secundando mis ideas, ponga todas sus miras, haga todos sus esfuerzos para que se acabe de una vez esta guerra, y así nos podremos ocupar del bien interior del país. Ahora espero que si no habrá recursos en abundancia, a lo menos no faltarán y se sabrá a punto fijo con lo que se cuenta. Respecto a la cooperación, me he convencido de que, si no la dan por ahora, la conseguiremos teniendo paciencia y constancia; bueno es trabajar siempre sobre esto; tú desde ahí y nosotros desde aquí. Istúriz está en esta idea; él te escribe con este mismo correo. Adiós: no puedo escribir más, pues esperan mi carta para que salga el correo. En tu adhesión y valor descansa MARIA CRISTINA." (...) Y en otra oportunidad, "la Reina, satisfecha esta vez con su Gobierno y con el acto que acababa de realizar, decía (...) a mi hermano: "Me alegro te hayan gustado las personas elegidas para el Ministerio; ellas no dudo corresponderán siempre, como hasta ahora lo hacen, a la confianza que en ellos tengo. Te escribirá Istúriz, creo, todo lo que ha ocurrido estos días y las causas que han producido la medida que hoy (23-V-1836) se ha tomado de disolver las Cortes; era imposible otra cosa, pues nunca, ni la felicidad de mi hija ni toda esta nación, podrán aconsejarme echarme en brazos de los revolucionarios".

La América y la Espafia Contemporánea Hispania Sacra 49 (1997) 
volví a Pamplona, adonde pedí al Barón de Meer un pasaporte para Madrid"62. Y el mando del ejército del Norte pasó a Espartero (1793-1879), quien, pese a utilizar la "Quinta de Mendizábal" o de los "Cien Mil", tuvo que sufrir la expedición del mariscal de campo carlista Miguel Gómez, que (desde Amurrio, Alava) apareció en Andalucía. Por ello Fernando de la Puente fue movilizado en la $2^{\mathrm{a}}$ Compañía de la Guardia nacional (29-IX-25-XI-1836) en Arcos de la Frontera. Aquí, a orillas del rio Majaceite, los carlistas fueron derrotados por los generales Ramón Narváez, Alaix y Rivero (25-XI-1836) ${ }^{63}$. Tal vez por eso Fernando de la Puente aparece en su citado expediente universitario como cura castrense de la parroquia de San Miguel de Sevilla (29-XII-1842): constan, de su puño y letra, las partidas matrimoniales (de 5-XII-1842 al sábado 15-IV1848) y bautismales (de 2-I-1843 al martes $2-\mathrm{V}-1848$ ) de dicha parroquia, hoy destruída por la piqueta desamortizadora.

Mas una vez desmovilizado, prosiguió con sus estudios teológicos hasta el doctorado (13-VI-1839), alternăndolos con la lengua griega (lo aprendido en 1834 fue ampliado con el catedrático José María Royo de 1843 a 1845) -en 1834 estudió hebreo--, dos cursos de Leyes (1837-1839) y Cánones (18391841), bachiller en Filosofia (1845), doctor en Letras (1847), y profesor sustituto de Teología (1836), catedrático de Teología (1847) y de Oratoria Sagrada (1838) y Lengua Inglesa (25-X-1845 al 10-IX-1847), amén de otras actividades académicas (bibliotecario desde 1844, etc.) y eclesiásticas (examinador sinodal del arzobispado hispalense en 1841 y del obispado de Canarias en 1844 , etc.). Pero el 12-V-1848 hubo de renunciar a todo al ser promovido a Ministro Auditor de número del supremo Tribunal de la Rota, reabierto por el gabinete presidido por Luis González Bravo (1811-1871) el 19-I-1844. Y fallecido el papa Gregorio XVI (15-VI-1846), quien no había enviado credenciales al nuncio Luigi Amat (1796-1878) ante Isabel II (por lo que marchó de Madrid a primeros de septiembre de 1835), el nuevo papa Pío IX (1846-1878) envió (marzo de 1847) a Giovanni Brunelli como delegado apostólico a Madrid y como primer nuncio ante Isabel II presentó sus credenciales (22-VII1848), superada la Regencia de Espartero ${ }^{64}$. Pero antes, Fernando de la Puente había sido testigo de la actuación del general Luis F. de Córdova en Sevilla (18-IX-1838, con el pronunciamiento del 11-XI-1838, la recepción de Ramón Narváez el 18-XI-1838 "con repique de campanas", hasta el 26-XI-1838, en que Córdova dejó Sevilla para exiliarse en Lisboa -25-III-1839-, donde falleció el 29-IV-1840) ${ }^{65}$.

\footnotetext{
62 CóRDOVA, $I b_{2}$, II, 122, 124-135.

63. CóRDOVA, $I b$., I, 263; II, 236-237. Cf. nota 1 .

64 CARCEL, El liberalismo..., 153-154. CoRdOVA, Ib., II, 440-467; III, 1-64.

65 CóRdova, $l b$., II, 271-272, 276, 286-436.
}

La América y la España Contemporánea

Hispania Sacra 49 (1997) 


\subsection{Episcopado de Fernando de la Puente.}

Fallecido Luis F. de Córdova y retirado de la política Mendizábal (en 1847, tras el regreso de su exílio hasta su muerte en noviembre de 1853), el gaditano Fernando de la Puente - con su gran bagaje intelectual- inicia su colaboración con el nuncio Brunelli -se estaba gestando el Concordato de 1851-, quien si cuando propuso al episcopado de Jaca (22-X-1848) a Miguel García Cuesta, no consiguió que Puente aceptara el de Urgel (por desconocimiento del catalán), le convenció para el de Salamanca, siendo consagrado obispo (19XII-1852): "a él --afirma el epicopólogo salmantino Vicente Bajo ${ }^{66}$ - se debe la restauración de la diócesis": tal restauración de la diócesis de Salamanca por el prelado Puente se encuadra en "extirpar con mano vigorosa los abusos que se habían introducido durante el largo período de la exclaustración, la desamortización (19-II-1836 y 29-VII-1837) y las guerras civiles que habían precedido: es imposibles describir lo mucho que hizo a favor de la Catedral - dio nuevos Estatutos al Cabildo-, Seminario - -"central", confiado a la dirección de los jesuitas-, parroquias, clero - terminó el expediente del Arrego parroquial, abrió concurso general completando la formación clerical con conferencias y ejercícios espirituales, amén de recordar la obligación de predicar y de catequizar todos los domingos y días festivos, de frecuentar los Sacramentos y de facilitarlos a los fieles-; a fin de animarles al cumplimiento de estos deberes y de auxiliarles en la práctica de los mismos, escribía pastorales, acomođadas a las necesidades para que las leyesen al pueblo, y [...] predicó no sólo en la Catedral, sino también en la misa conventual de las parroquias de la ciudad altemativamente por espacio de dos años, confesando además en su capilla a los fieles que deseaban recibir los Santos Sacramentos de sus manos; dio modelos para extender con uniformidad las partidas Sacramentales en los libros parroquiales; conforme a los presupuestos de cada parroquia se rendían cuentas anuales de los ingresos de fábrica y de los demás gastos, con noticia de los censos, aniversarios y cargas piadosas que estuviesen sin cumplir, indicando el procedimiento a emplear con los morosos; formó y arregló la colecturía de misas en la Secretaría de Cámara; para entenderse más fácilmente con el clero fundó el Boletín eclesiástico, tal vez el primero que se estableció en España. Visitó toda la diócesis. Tenía ordenado a los párrocos de la ciudad que le pasasen recado de los enfermos viatificados, a los que visitaba los domingos y les confortaba con los auxilios espirituales y corporales según la necesidad. Recibía y oía, por regla general, en las horas marcadas, a todos los que le pedían audiencia [...]. Su vida privada, según nos manifiesta nuestro amigo D. Fernando Iglesias, Canónigo de la Santa Catedral de Zamora, que fue su inti-

66 J. A. VICENTE BAJO, Espiscopológio salmantino, Impr. Calatrava, Salamanca 1901, 227-230. 
mo familiar, era austera, penitente y laboriosa. Se levantaba en todo tiempo a las cuatro de la mañana y se preparaba para la celebración de la santa misa con una hora de oración mental. Ayunaba frecuentemente y su comida era parca. Estando en Salamanca fue elegido con el Cardenal [Miguel García] Cuesta [arzobispo de Santiago de Compostela, 1851-1873] por el gobierno para que representasen en Roma (1854) al episcopado español en el acto de la declaración dogmática de la Inmaculada."

El ya citado episcopólogo burgalés, Manuel Martínez Sanz ${ }^{67}$, y orador fúnebre en las honras que el Seminario dedicó al cardenal Puente (3-VI-1867), resume su biografia: "Preconizado Arzobispo de Burgos el 25-IX-1857, tomó posesión por Procurador el 1-I-1858, e hizo su entrada pública el 7-II-1858. Estaba condecorado con las grandes cruces de Carlos III y de Isabel la Católica. Fue preconizado Cardenal Presbítero por la Santidad de Pío IX el 27-IX1861 , y el $21-\mathrm{V}-1862$ fue investido por S.S. con el capelo cardenalício, recibiendo el título de Santa María de la Paz; en 29-X-1864 fue nombrado confesor y director de la enseñanza moral y religiosa de D. Alfonso [...]. En tiempo de este Prelado [...] se hizo en Burgos la fundación de las Adoratrices y esclavas del Santísimo Sacramento [...], se embaldosó con mármol de Carrara todo el templo Catedral; se hizo de nuevo la escalinata para subir a la puerta del Sarmental y se colocó al pie de la misma la gran reja que importó en su colocación 40.124 reales, costeados por el Prelado. Se construyó la mayor parte del edificio nuevo del Seminario Conciliar, al que dejó heredero de sus bienes. Mejoró notablemente el interior del palacio Arzobispal. Murió en Madrid el 12-III-1867. Se trajo el cadáver a esta Ciudad y se hizo el entierro solemne después de haber estado tres días espuesto [sic] en la capilla Arzobispal, el 18 del mismo mes. Se celebraron honras (en la S.I. Metropolitana) el 30 del siguiente Abril y pronunció la oración fúnebre el Dr. D. Félix Martínez e Izarra, Tesorero de la Santa Iglesia y secretario que fue del difunto Prelado [...]. El cadáver está en la Catedral en un sepulcro de mármol con la correspondiente inscripción, en la capilla de Nuestra Señora de los Remedios, que hoy se titula del Santísimo Cristo."

Podemos completar su actividad pastoral con nuestro trabajo, ya mencionado, "El Cardenal Puente, antecedente de nuestra Facultad": en él recurrimos a dicha oración fúnebre de Félix Martínez e Izarra, que además fue su Gobernador eclesiástico durante sus ausencias: aquí nos describe su actuación en la parroquia sevillana de San Miguel antes de 1848, donde "para el socorro de los necesitados fundó una asociación muy parecida a la que hoy se conoce con el nombre de

67 Boletin Eclesiástico del Arzobispado de Burgos (BEAB) XVII (27-X-1874) 205-206.

La América y la España Contemporánea Hispania Sacra 49 (1997) 
Conferencias de San Vicente de Paúl", entre muchas iniciativas que realizó en la ciudad hispalense, alternando con su abundante actividad universitaria.

Tal actuación en la Universidad de Sevilla - a la que ya nos hemos referido- como en la Rota y en el obispado salmantino, elaboró en aquel joven formado en Inglaterra un talante episcopal que el historiador Cuenca Toribio ${ }^{68}$ para calificarlo, no halla otra terminología como la de "una figura reciamente evangélica". Y opinamos que, si otros contemporáneos suyos como Fernando Fernández de Córdova (1809-1883) ( $^{69} 1860$ supieron intuir la "marcha de las ideas y el influjo de la opinión", el cardenal Puente supo escrutar el signo de los tiempos al hallarse en contacto con su pueblo (en las Visitas Pastorales a sus diocesanos de Salamanca y Burgos) y en la corte. Especialmente en la corte supo oír la campanada del reloj de la historia que en las Cortes gaditanas Diego Muñoz Torrero, en su discurso inaugural, hizo caer el telón del Antíguo Régimen hacia una sociedad nueva, con muchas nubes - la primera represión de Fernando VII, y la segunda tras el trienio constitucional (1820-1823), además de los obstáculos de la Regente María Cristina a Mendizábal en su proceso desamortizador; y después de la corta Regencia de Espartero y del bienio progresista (1854-1856) los gabinetes moderados de Isabel II no impedirán la nueva sociedad española con el estruendo de la "Septembrina" de 1868-.

Los "cincuenta años" que Mendizábal quería recorrer rápidamente, llegaron después de su muerte, pero no dudamos que el talante episcopal -"evangélico"- del cardenal Puente planteó una vivencia eclesial nueva en su múltiple actividad en el arzobispado burgalés desde su llegada el viernes 5- 1 - $1858^{70}$ ante las 1.213 parroquias, 75.086 vecinos y 318.383 almas $^{71}$, abriendo su primera Visita Pastoral el 18-IV-1858 ${ }^{72}$-interrumpida por enfermedad para viajar a su "país natal", Cádiz ${ }^{73}$-, que acabará poco antes de su muerte: concluída tal Visita el 28-VII-1866 ${ }^{74}$, ya en la corte ${ }^{75}$, fallece el 12-III-186776.

Muy vinculado a Pío IX (1846-1878), se hace eco de todas sus alocuciones y preocupaciones desde el $18-\mathrm{VI}-1859^{77}$ en defensa del poder temporal del

68 J. M.CUENCA TORIBjo, Iglesia y poder politico. La era isabelina y el sexenio democrático (1834-1878), Historia de España, Espasa-Calpe S.A., Madrid 1988, 2 ed., t. XXXIV, p. 611.

69 Córdova, $I b$., III, 452.

70 BEAB I (6-II-1858) 63-64.

7 BEAB I (3-IV-1858) 234.

72 BEAB I (1-V-1858) 249-253.

73 BEAB IV (4-IV-1861) 129-130.

74 BEAB IX (2-VIII-1866) 225.

75 BEAB IX (1-XI-1866) 321.

76 BEAB X (13-III-1867) 89.

77 BEAB II (16-VII-1859) 417-428; (6-VIII-1859) 433-436; (15-X-1859) 521-529; III (19-I1860) 17-20; (16-II-1860) 49-62; (1-III-1860) 65-69; (15-III-1860) 92-93; (15-IV-1860) 124-125; (3- 
Romano Pontífice para "poder con amplísima libertad apacentar y regir toda la grey del Señor"; y, sobre todo, del "non possumus"78 - a partir de 1861 el cardenal Puente seguirá siendo su resonador hasta su muerte--. Insistimos en el talante "evangélico" de nuestro cardenal: trasciende el encasillado de Martín Tejedor ${ }^{79}$ acerca del episcopado hispano - generación desamortizada y africana-: fue el primer prelado español, consultado (en la primavera de 1865) por Pío IX sobre el Concílio Vaticano I, quien plantea el tema de la infalibiidad pontifícia y su defensa del poder temporal del Papa constituía un instrumento para conservar la independencia de su actividad religiosa en el universo, quedando así garantizada por el dogma de la infalibilidad pontifícia: "Cuando nosotros - dice a sus diocesanos el (26-IV-186080 - abogamos por la integridad de los derechos, y la independencia Soberana del Romano Pontífice, no son tan sólo sus intereses los que defendemos, son también los intereses espirituales del Catolicismo: son derechos que tenemos doscientos millones de católicos, a que nuestro Jefe espiritual nos gobierne con entera libertad, según le dé a entender el Espíritu Santo, que constantemente le asiste y le ilumina." Con su talante, sin excluir la problemática que vivió ante la guerra

V-1860) 129-141; (7-VI-1860) 165-167; (21-VI-1860) 193-195; (5-VIl-1860) 210-212; (19-VII1860) 214-227; (2-VIII-1860) 230-243; (16-VIII-1860) 245-257; (27-VIII-1860) 271-276; (6-IX1860) 289-291; (4-X-1860) 319-323; (1-XI-1860) 341-356; IV (3-I-1861) 13-14; (7-II-1861) 51-59; (21-III-1861) 112-113; (4-IV-1861) 117-126, 131; (18-IV-1861) 142-146; (16-V-1861) 186-188; (6VI-1861) 195-206; (20-VI-1861) 212-217; (1-VIII-1861) 255-256; (19-IX-1861) 321; (17-X-1861) 339-344: CARDENAL; (7-XI-1861) 360-363; V (16-1-1862) 28-31; (6-III-1862) 65-70, 76; (20-III1862) 81-83; (3-IV-1862) 97-101; (16-IV-1862) 113-122, 126-127; (1-V-1862) 129; (5-VI-1862) 161-168, 173-174; (20-VI-1862) 177-192; (3-VII-1862) 217-230; (7-VIII-1862) 193-201, 246-247; (2I-VIII-1862) 249-252; (18-IX-1862) 281-287; (16-X-1862) 315-316; (18-XII-1862) 377-378; VI (1-I-1863) 12-13; (15-I-1863) 28-30; (5-III-1863) 66-74; (2-IV-1863) 97-107; (16-IV-1863) 125; (16 VII-1863) 223-224; (6-VIII-1863) 225-226, 234; (17-IX-1863) 273-283; (19-XI-1863) 377-344; (17XII-1863) 380-381; VII (7-I-1864) 11-13; (21-I-1864) 29-32; (4-II-1864) 42-43; (18-II-1864) 63; (22VII-1864) 221-222; (1-IX-1864) 258-264; (17-XI-1864) 337-343; (1-XII-1864) 364-366; VIII (18-I1865) 18-40; (1-II-1865) 55; (2-III-1865) 74-76; (16-III-1865) 89-94; (6-IV-1865) 106-117; (20-IV1865) 122-133; (4-V-1865) 152,167; (6-VII-1865) 201-207; (20-VII-1865) 220-225; (4-VIII-1865) 234-239; (17-VIII-1865) 262-264; (5-X-1865) 297-306; (19-X-1865) 314-325; (31-XII-1865) 416; IX (25-I-1866) 22-24; (1-II-1866) 33-43; (5-IV-1866) 98-104; (19-IV-1866) 113-128; (3-V-1866) 129134; (16-VII-1866) 207-208; (16-VIII-1866) 255-256; (6-IX-186) 270-272; (15-XI-1866) 337-344, 349-350; (29-XI-1866) 353-358; (31-XII-1866) 406-408; X (21-I-1867) 18-29; (21-II-1867) 50-54. Cf. A. MarTinez ALBIACH, Del poder temporal a la infalibilidad pontificia de Pto IX desde España: "Burgense" 20/1 (1979) 179-286.

78 BEAB IV (4IV-1861) 122; IX (15-XI-1866) 340.

79 J. MARTIN TEJEDOR, Concílio Vaticano 1. Diccionario de Historia Eclesiástica de España, C.S.L.C., Madrid 1972, t.I, p.496-515. R. AUBERT, El Concílio Vaticano I. Nueva Historia de la Iglesia, Cristiandad, Madrid 1984, 69-74. M. TREvor, John H. Newman, crónica de un amor a la verdad, Sigueme, Salamanca 1989, 249-274. CARCEL, El liberalismo..., 190-193.

Bo BEAB III (3-V-1860) 133.

La América y la España Contemporánea

Hispania Sacra 49 (1997) 
"africanista"81 como con el Convenio de 25-VIII-185982 y otros "sucesos" (enfrentamiento a O'Donnell por el reconocimiento del Rey de Italia, su destitución de su cargo junto al futuro Alfonso XII, su posterior rehabilitación, etc.) trasciende cualquier encasillado en comparación con sus otros hermanos en el episcopado.

Si Luis Fernández de Córdova alcanza su cenit en Mendigorría y Arlabán en la primera guerra carlista - durante la cual fue movilizado Fernando de la Puente en la Quinta de Mendizábal--, y éste adquiere su renombre en el tema desamortizador, nuestro cardenal Puente consigue su prestigio como visionario de los signos de su tiempo, alcanzando una altura similar a la de sus paisanos y contemporáneos, si bien en tres líneas divergentes: tres gaditanos que, cada uno desde su vivencia profesional, otearon el horizonte de una sociedad española nueva, pues el telón del Antíguo Régimen había caído definitivamente.

81 BEAB II (19-XI-1859) 564567; (17-XII-1859) 602-603; III (19-I-1860) 31-32; (2-II-1860) 46-47; (16-II-1860) 63-64; (15-III-1860) 95; (21-VI-1860) 187-190.

82 BEAB III (10-I-1860) 21-27; (19-IV-1860) 123-124.

La America y la España Contemporánea Hispania Sacra 49 (1997) 